\title{
Momen Inersia Sebagai Indikator Untuk Mendeteksi Kegagalan Sistem Transfer Cake Breaker Conveyor
}

\author{
Alkadri masnur ${ }^{1)}$, M.Khairul Anam ${ }^{2)}$ \\ ${ }^{1,2}$ Teknik Informatika, STMIK Amik Riau, Jl.Purwodadi Indah Km. 10 Panam Pekanbaru \\ Email: ${ }^{\text {alkadrimasnur@stmik-amik-riau.ac.id }},{ }^{2}$ khairulanam@ @stmik-amik-riau.ac.id
}

\begin{abstract}
The Palm Oil Mill has several processing stations, one of which is the press station, at the press station there is a unit of Cake Breaker Conveyor $(C B C)$ which serves to break up the pulp from the press machine, in CBC there is also the separation of pulp and nuts Palm oil). For 1 unit of Cake Breaker Conveyor (CBC) with a length of 30 meters, serving 4 press machines. Clumps of pulp from the press machine have a temperature of $98^{\circ} \mathrm{C}$, with heavy loads and high temperatures, the Cake Breaker Conveyor (CBC) often experiences transfer failure due to the breakdown of As-screw. If a transfer failure occurs, the oil palm pulp will accumulate at the press point of the press, besides the boiler fuel feed is interrupted because the palm oil pulp is not delivered to the fuel furnace. At the time of the transfer failure at $C B C$ there is a law of inertia or moment of inertia on the object rotating on its axis, the moment of inertia that occurs in the CBC can be detected by the Rotary Encoder. Fuzzy Tsukamoto's logic can take into account As-screw breaking points on the Cake Breaker Conveyor $(C B C)$ by utilizing the moment of inertia and $C B C$ motor rotation speed as input while the output is the As-Screw breaking point on the 30 Meter $C B C$.
\end{abstract}

Keywords:Cake Breaker Conveyor(CBC), law inertia, As-screw, Fuzzy Tsukamoto

\begin{abstract}
Abstrak
Pabrik Kelapa Sawit memiliki beberapa stasiun pengolahan salah satunya adalah stasiun kempa/press, pada stasiun kempa terdapat satu unit mesin Cake Breaker Conveyor (CBC) yang berfungsi memecah gumpalan ampas dari mesin kempa/press, pada CBC terjadi juga pemisahan ampas dan nuts (inti biji kelapa sawit). Untuk 1 unit Cake Breaker Conveyor (CBC) dengan panjang 30 meter, melayani 4 mesin press. Gumpalan ampas dari mesin kempa/press memiliki suhu $98^{\circ} \mathrm{C}$, dengan beban yang berat dan suhu yang tinggi maka Cake Breaker Conveyor (CBC) sering mengalami kegagalan transfer akibat putusnya As-screw. Jika terjadi kegagalan transfer maka ampas kelapa sawit akan menumpuk pada titik pembuangan mesin press, selain itu umpan bahan bakar boiler tergangu karena ampas kelapa sawit tidak terkirim ke tungku bahan bakar. Pada saat terjadinya kegagalan transfer pada CBC terjadilah hukum kelembaman atau momen inersia pada benda yang berotasi pada porosnya, momen inersia yang terjadi pada CBC dapat dideteksi oleh Rotary Encoder. Logika Fuzzy Tsukamoto dapat memperhitungkan titik putus nya As-screw pada Cake Breaker Conveyor (CBC) dengan memanfaatkan momen inersia dan kecepatan putaran motor CBC sebagai input sedangkan output adalah titik putusnya As-Screw pada CBC sepajang 30 Meter.
\end{abstract}

Kata kunci: Cake Breaker Conveyor,Momen Inersia, As-Screw, Fuzzy Tsukamoto

\section{PENDAhULUAN}

Kelapa sawit yang memiliki nama latin Elaeis Guineensis adalah tanaman perkebunan yang dapat diolah menjadi minyak masak, minyak industri dan bahan bakar diesel yang lebih dikenal dengan Biodiesel. Menurut (Iswanti et al., 2012) Kelapa sawit merupakan tanaman perkebunan yang dapat menghasilkan minyak nabati disamping tanaman kacang-kacangan dan jagung. Jadi kelapa sawit adalah tanaman yang memiliki banyak manfaat bagi masyarakat namun dibutuhkan pengolahan dari tanda buah segar kelapa sawit menjadi minyak mentah/Crude Palm Oil (CPO) dan produk turunan lainnya. Minyak mentah kelapa sawit memiliki kandungan mineral alami, menurut (Setyopratomo, 2012) 
komponen utama $\mathrm{CPO}$ adalah Trigliserida dengan kandungan $93 \%$ kandungan gliserida yang lain dalam CPO adalah digliserida $4,5 \%$ dan monolgriserida $0,9 \%$. Pabrik kelapa sawit memiliki proses pengolahan, Menurut (Upriyono et al., 2008) proses pengolahan kelapa sawit dari tandan buah segar (TBS) hingga dihasilkan CPO dan inti sawit melalui beberapa stasiun pengolahan yang dapat dibagi menjadi 3 tahapan sebagai berikut:

a. Tahapan Pengolahan Awal

b. Tahapan Pengolahan CPO

c. Tahapan Pengolahan Inti Sawit

Pada tahapan pengolahan awal pabrik kelapa sawit (PKS) memiliki stasiun kempa yang berfungsi untuk memisahkan minyak mentah kelapa sawit Crude Palm Oil (CPO) dari ampas dan cangkang kelapa sawit. Stasiun kempa memiliki unit yang digunakan untuk memisahkan ampas dan nuts kelapa sawit yaitu unit Cake Breaker Conveyor (CBC). Menurut (Agus Suandi, Nurul Iman Supardi, 2016) unit Cake Breaker Conveyor berfungsi sebagai pemisah ampas kempa Ampas hasil press yang masih bercampur nuts dan berbentuk gumpalan - gumpalan dipecah dan dibawa untuk dipisahkan antara ampas dan nuts. Pada pabrik kelapa sawit kapasitas 30 ton/jam memiliki 1 unit CBC sedangkan pada pabrik kelapa sawit kapasitas 60 ton/jam memiliki 2 unit CBC. Setiap 1 unit CBC memiliki panjang 30 meter untuk melayani 4 mesin press yang akan mentransfer ampas kelapa sawit tersebut ke stasiun bahan bakar boiler. Menurut (Okafor, 2015) Suhu ampas kelapa sawit sebelum dilakukan pemisahan sekitar $98^{\circ} \mathrm{C}$ suhu ini didapat dari proses digester, jika unit Screw putus atau terjadi kegagalan pada transfer maka ampas kelapa sawit yang dikeluarkan dari mesin press akan menumpuk pada masing - masing terminal press, dan menghambat proses pengiriman bahan bakar ke boiler yang akan berdampak berhentinya pabrik. Apabila terjadi kegagalan transfer pada unit cake breaker conveyor unit screw yang terpisah dengan motor listrik akan mempertahankan posisinya yang disebut yang dikenal dengan moment inersia atau kelembaban. Menurut (Rahmawati, Teknik, Alat, \& Balikpapan, 2012) momen inersia adalah perilaku dinamis dari sebuah kerangka yang berputar pada sebuah sumbu. Maka jika suatu benda berputar pada porosnya kemudian terputus dari sumber daya putar maka dia akan mempertahankan daya putaran terakhir sampai akhinya berhenti.

\section{METODE PENELITIAN}

Metode penelitian yang dilakukan menggunakan Framework yang ditunjukan pada gambar 1 .

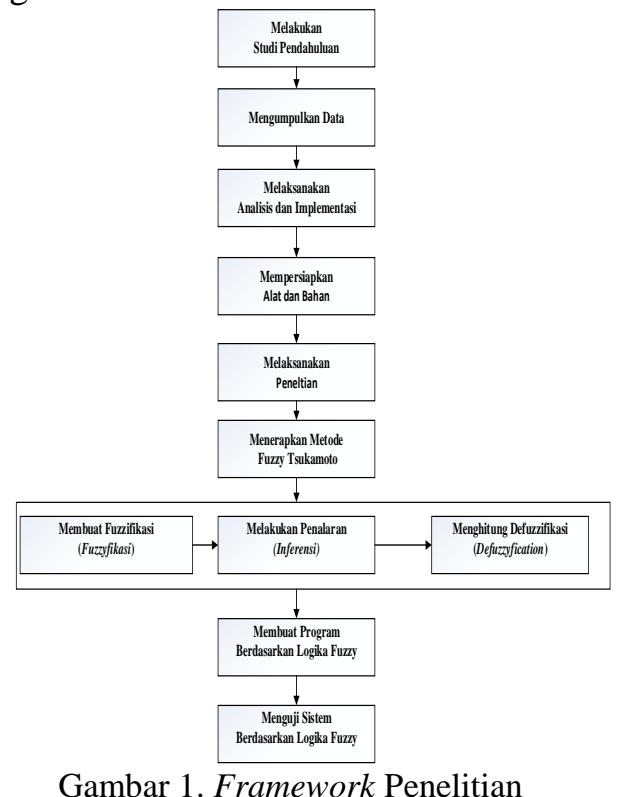

a. Studi pendahuluan, dilakukan untuk mempertajam arah studi utama. Hal-hal yang dilakukan pada studi pendahuluan adalah studi literatur, wawancara dengan operator dan studi tempat penelitian

b. Mengumpulkan data, Penelitian akan memperoleh tujuan yang diharapkan apabila didukung oleh data yang valid (sahih) dan reliabel.

c. Melaksanakan analisis teknik pelaksanaan Analisis dan implementasi, dinyatakan dengan pembuatan laporan penelitian dari level perencanaan, perancangan hingga proses implementasi penelitian dengan asumsi penelitian telah selesai dilakukan.

d. Mempersiapkan Alat dan bahan yang digunakan untuk membuat model penelitian berbasis fuzzy dengan Inferensi Tsukamoto untuk menetukan titik putusnya atau gagalnya sistem transfer pada Cake Breaker Conveyor(CBC).

e. Melaksanakan penelitian yang dilakukan untuk membuat model dan protype yang 
dapat bekerja berdasarkan logika Fuzzy dengan Inferensi Tsukamoto.

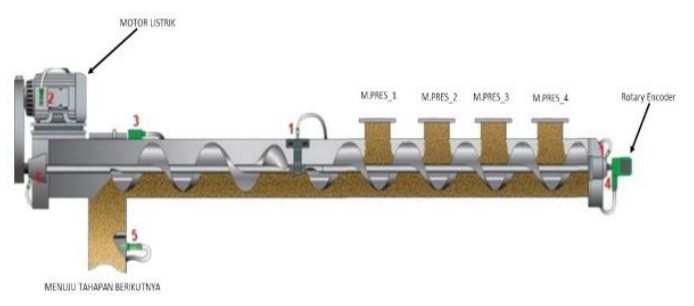

Gambar 2. Model prototype CBC

f. Menerapkan Logika Fuzzy Tsukamoto, Penerapan Logika Fuzzy Tsukamoto pada unit Cake Breaker Conveyor (CBC) mengikuti beberapa tahapan sebagai berikut

1) Komponen variabel input kecepatan motor CBC memiliki variabel linguistik Lambat, Sedang dan Cepat dengan nilai fuzzyfikasi $(0-50 \mathrm{rpm})$ lambat, (30 - $70 \mathrm{rpm})$ sedang dan (50 $-70 \mathrm{rpm})$ Cepat.

2) Komponen variabel input waktu deteksi rotary encoder memiliki variable linguistik Singkat, Sedang dan Lama dengan nilai $0-50 \mathrm{~ms}$ singkat, 25 - $75 \mathrm{~ms}$ sedang dan 50 - 75ms cepat didapat dari momen inersia.

3) Komponen variabel output posisi deteksi pada ulir Cake Breaker Conveyor dengan panjang 30 Meter, memiliki variabel linguistik Kuadran I, Kuadran II dan Kuadran III dengan nilai 0 - 20 KuadranI, 10 - 30 Kuadran II dan 20 - 30 Kuadran III

4) Menetukan inferensi atau rules yang diharapkan untuk memprediksi titik putusnya As-Screw pada Cake Breaker Conveyor.

5) Menentukan nilai Crisp dari melalui Defuzzyfikasi dengan rumus sebagai berikut :

$$
z=\frac{\sum \alpha_{1 .} z_{1}}{\sum \alpha_{1}}
$$

Dimana :

$$
\begin{aligned}
& \mathrm{Z}=\text { nilai rata } \\
& \alpha 1=\text { nilai dari prediket } \\
& \mathrm{z} 1=\text { nilai dari rule }
\end{aligned}
$$

g. Membuat program menggunakan sistem logika Fuzzy dengan Inferensi Tsukamoto ditujukan agar program tersebut dapat mengetahui kegagalan sistem transfer Cake Breaker Conveyor(CBC) berdasarkan logika Fuzzy dengan Inferensi Tsukamotor agar deteksi putusnya dapat diketahui dengan cermat.

h. Menguji program menggunakan prinsip logika Fuzzy dengan Inference Tsukamoto langkah berikutnya adalah menguji sistem berdasarkan titik putusnya Cake breaker Conveyor (CBC) target ukurnya adalah deteksi yang didapat harus sama dengan prediksi dengan toleransi maksimal 10\%

\section{HASIL DAN PEMBAHASAN}

a. Fuzzyfikasi variabel input dan output

Variabel yang digunakan untuk variable input yaitu kecepatan putaran motor CBC dan waktu deteksi yang didapat dari rotary encoder sedangkan veriabel output adalah titik ulir pada CBC sepanjang 30 Meter.

a. Variable Kecepatan Putaran Motor CBC

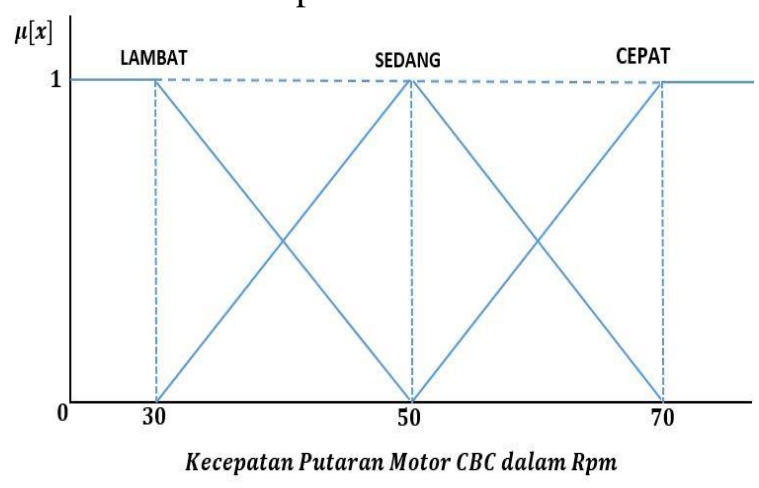

Gambar 3. Keanggotaan Putaran Motor CBC

$$
\begin{gathered}
\mu_{\mathrm{M} l}(x)\left\{\begin{array}{l}
1 \\
(50-x) /(50-30) \\
0
\end{array}\right. \\
\mu M s(x)\left\{\begin{array}{l}
(x-30) /(50-30) \\
1 \\
(70-x) /(70-50) \\
0
\end{array}\right. \\
\mu_{M c}(x)\left\{\begin{array}{l}
0 \\
(x-50) /(70-50) \\
1
\end{array}\right.
\end{gathered}
$$$$
\begin{aligned}
& ; 0 \leq x \leq 30 \\
& ; 30<x<50 \\
& ; x \geq 50
\end{aligned}
$$$$
; 30<x<50
$$$$
\text { ; } x=50
$$$$
; 50<x<70
$$$$
; \quad x \leq 30 \text { atau } x \geq 70
$$$$
\text { ; } x \leq 50
$$$$
\text { ; } 50<x<70
$$$$
\text { ; } x \geq 70
$$ 
b. Variabel Waktu Deteksi Rotary Encoder

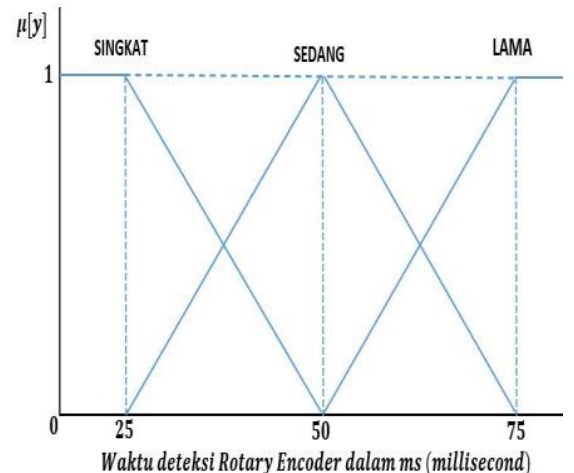

Gambar 4. Keanggotaan Waktu Deteksi Rotary Encoder

$$
\begin{gathered}
\mu_{E s i}(y) \begin{cases}1 & ; 0 \leq y \leq 25 \\
(50-y) /(50-25) & ; 25<y<50 \\
0 & ; y \geq 50\end{cases} \\
\mu_{E s e}(y) \begin{cases}(y-25) /(50-25) & ; 25<y<50 \\
1 & ; y=50 \\
(75-y) /(75-25) & ; 50<y<75 \\
0 & ; y \leq 25 \text { atau } y \geq 75\end{cases} \\
\mu_{E l}(y) \begin{cases}0 & ; y \leq 50 \\
(y-50) /(75-50) & ; 50<y<75 \\
1 & ; y \geq 75\end{cases}
\end{gathered}
$$

c. Variabel Output posisi deteksi pada ulir Cake breaker conveyor $(\mathrm{CBC})$

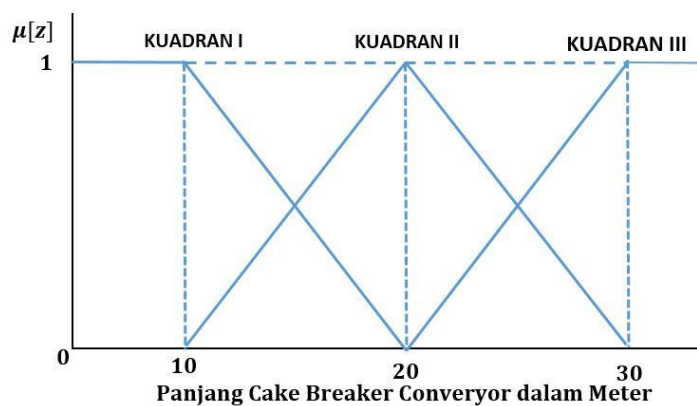

Gambar 5. Keanggotaan Panjang Cake Breaker Conveyor

$$
\begin{aligned}
& \mu_{K I}(z)\left\{\begin{array}{l}
1 \\
(20-z) /(20-10) \\
0
\end{array}\right. \\
& \mu_{K I I}(Z)\left\{\begin{array}{l}
(Z-10) /(20-10) \\
130-z) /(30-20) \\
0
\end{array}\right. \\
& \mu_{K I I I}(Z)\left\{\begin{array}{l}
0 \\
(z-20) /(30-20) \\
1
\end{array}\right.
\end{aligned}
$$

$$
\begin{aligned}
& ; 0 \leq z \leq 10 \\
& ; 10<z<20 \\
& ; y \geq 20 \\
& ; 10<z<20 \\
& ; z=20 \\
& ; 20<z<30 \\
& ; z \leq 10 \text { atau } z \geq 30 \\
& \quad ; y \leq 20 \\
& \quad ; 20<y<30 \\
& ; y \geq 30
\end{aligned}
$$

\section{b. Penetuan rules}

Rules dibuat sebagai aturan atau metode yang harus diikuti variabel fuzzy yang telah selesai ditetapkan. Rules yang dibuat menggunakan logika Fuzzy Tsukamoto untuk menentukan titik kegagalan sistem transfer Cake Breaker Conveyor (CBC) adalah sebagai berikut :

[R1] If Putaran Motor Lambat And Deteksi Rotary Singkat Then Kuadran I [R2] If Putaran Motor Sedang And Deteksi Rotary Singkat Then Kuadran I

[R3] If Putaran Motor Cepat And Deteksi Rotary Singkat Then Kuadran I

[R4] If Putaran Motor Lambat And Deteksi Rotary Sedang Then Kuadran I

[R5] If Putaran Motor Sedang And Deteksi Rotary Sedang Then Kuadran II

[R6] If Putaran Motor CepatAnd Deteksi Rotary Sedang Then Kuadran II

[R7] If Putaran Motor Lambat And Deteksi Rotary Lama Then Kuadran II

[R8] If Putaran Motor SedangAnd Deteksi Rotary Lama Then Kuadran III

[R9] If Putaran Motor Cepat And Deteksi Rotary Lama Then Kuadran III

\section{c. Penegasan (Defuzzification)}

Penegasan atau defuzzifikasi adalah penentuan nilai tegas yang dihitung berdasarkan jumlah nilai predikat dikalikan dengan nilai rules dibagi jumlah predikat. Menggunakan rumus sebagai berikut :

$$
Z=\frac{(a 1 * z 1+a 2 * z 2+a 3 * z 3+a 4 * z 4+a 5 * z 5+a 6 * z 6+}{a 7 * z 7+a 8 * z 8+a 9 * z 9)}
$$

d. Pengolahan data menggunakan Fuzzy dengan Inferensi Tsukamoto

Pengolahan data menggunakan Fuzzy Tsukamoto pada putaran motor cbc $37 \mathrm{rpm}$ dan waktu deteksi encoder $55 \mathrm{~ms}$. Pada meter keberapakah terjadi kegagalan transfer CBC tersebut?

a. Fuzzyfikasi pada putaran motor CBC 37 rpm

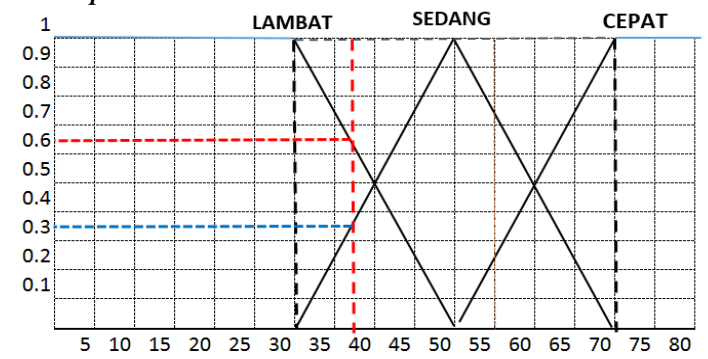

Gambar 6. Fuzzifikasi 37 Rpm 
Nilai pada Motor Lambat $=0,65$

Motor Sedang $=0,35$

Motor Cepat $=0,0$

b. Fuzzifikasi Deteksi Waktu Rotary Encoder 55ms

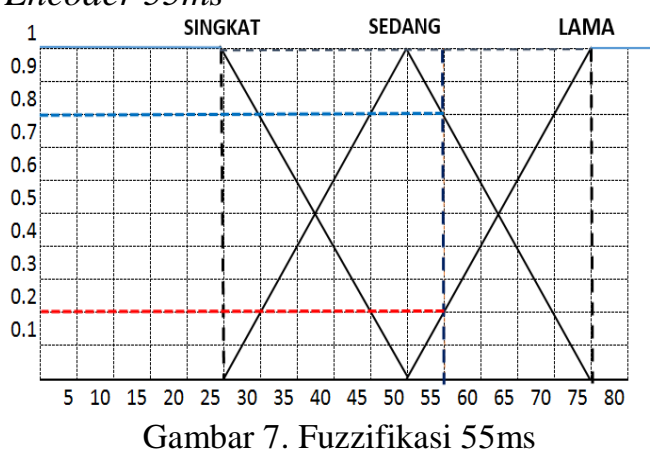

Nilai waktu deteksi

Rotary Encoder Singkat = 0,0

Sedang $=0,8$

Lama $=0,2$

c. Penalaran (Inference)

$[\mathrm{R} 1] \alpha 1=0 \quad$ rules $=20$

$[\mathrm{R} 2] \alpha 2=0 \quad$ rules $=20$

$[\mathrm{R} 3] \alpha 3=0 \quad$ rules $=20$

$[\mathrm{R} 4] \alpha 4=0.65$ rules $=13.5$

$[\mathrm{R} 5] \alpha 5=0.35$ rules $=20$

[R6] $\alpha 6=0 \quad$ rules $=20$

$[\mathrm{R} 7] \alpha 7=0.20$ rules $=20$

[R8] $\alpha=0.20$ rules $=22$

$[\mathrm{R} 9] \alpha 9=0 \quad$ rules $=20$

d. Penegasan (Defuzzyfikasi)

$$
\begin{aligned}
& \mathrm{Z}=\frac{(0 * 20+0 * 20+0 * 20+0,65 * 13,5+0,35 * 20+}{0 * 20+0,20 * 20+0,20 * 22+0 * 20)} 0+0+0+0,65+0,35+0+0,20+0,20+0 \\
& \mathrm{Z}=\frac{24,1750}{1,40}=17.26 \text { meter }
\end{aligned}
$$

Hasil penelusuran pengolahan data menggunakan logika fuzzy dengan sistem Inferensi Tsukamotor didapatkan hasil sistem mengalami gagal transfer pada titik 17,26 meter atau terletak pada kudran I.

e. Perhitungan menggunakan aplikasi berbasis desktop

Aplikasi deteksi titik putusnya screw-as CBC dibangun menggunakan Program Visual basic, menggunakan bahasa pemrograman basic dan penerapan logika fuzzy dengan sistem Inferensi Tsukamoto. Tolok ukur pengujian aplikasi yang akan dibuat adalah sebagai berikut : a) Jika waktu deteksi rotary encoder singkat dan putaran motor lambat hasilnya pada kuadran I

b) Jika waktu deteksi rotary ecoder sedang dan putaran motor sedang hasilnya pada kuadran II

c) Jika waktu deteksi rotary encoder lama dan putaran motor cepat maka hasilnya pada kuadran III

\section{a. Software Aplikasi}

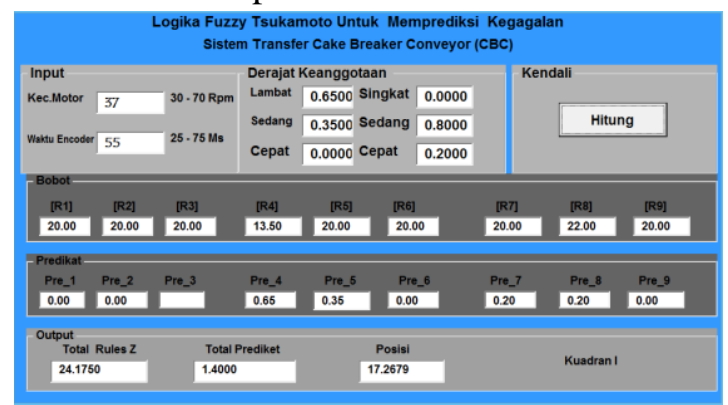

Gambar 8. Software aplikasi deteksi kegagalan system transfer cake breaker conveyor.

Hasil perhitungan software aplikasi dengan perhitungan manual memdapatkan hasil yang sama yaitu 17,26 Meter tepat pada posisi kuadran I. Apakah logika fuzzy dengan Inferensi Tsukamoto dapat memberikan hasil sesuai dengan harapan dasar control deteksi putusnya as-screw pada CBC selanjutnya kita akan menggunakan data uji lebih lanjut pada tabel 1.

\section{f. Data Analisis Penentuan Kuadran}

Untuk pengujian lebih detail dilakukan uji coba data menggunakan 9 data sebagai berikut:

Tabel 1. Uji data penentuan kuadran

\begin{tabular}{|c|c|c|c|}
\hline No & $\begin{array}{l}\text { Kecepatan } \\
\text { (CBC) }\end{array}$ & $\begin{array}{l}\text { Waktu Deteksi } \\
\text { Rotary Encoder }\end{array}$ & $\begin{array}{l}\text { Prediksi } \\
\text { Output }\end{array}$ \\
\hline 1 & 35 & 26 & KI \\
\hline 2 & 40 & 27 & KI \\
\hline 3 & 55 & 28 & KI \\
\hline 4 & 36 & 40 & KI \\
\hline 5 & 45 & 45 & KII \\
\hline 6 & 60 & 55 & KII \\
\hline 7 & 40 & 60 & KII \\
\hline 8 & 55 & 65 & KIII \\
\hline 9 & 65 & 68 & KIII \\
\hline
\end{tabular}


Penentuan kuadran pada titik putus nya CBC sebagai berikut:
a. Nilai $(10<=$ Kuadran I $<18)$
b. Nilai $(18<=$ Kundran II $<22)$
c. Nilai $(22<=$ Kuadran III $<30)$

Tabel 2. Hasil uji data penentuan kuadran

\begin{tabular}{|c|c|c|c|c|}
\hline No & $\begin{array}{c}\text { Kecepatan } \\
\text { (CBC) }\end{array}$ & $\begin{array}{c}\text { Waktu } \\
\text { Rotary } \\
\text { Encoder }\end{array}$ & $\begin{array}{c}\text { Prediksi } \\
\text { Output }\end{array}$ & $\begin{array}{c}\text { Hasil } \\
\text { Output }\end{array}$ \\
\hline 1 & 35 & 26 & KI & 14,1981 \\
\hline 2 & 40 & 27 & KI & 15,6345 \\
\hline 3 & 55 & 28 & KI & 14,9597 \\
\hline 4 & 36 & 40 & KI & 16,1875 \\
\hline 5 & 45 & 45 & KII & 18,9821 \\
\hline 6 & 60 & 55 & KII & 20,5714 \\
\hline 7 & 40 & 60 & KII & 19,5000 \\
\hline 8 & 55 & 65 & KIII & 22,8167 \\
\hline 9 & 65 & 68 & KIII & 23,8727 \\
\hline
\end{tabular}

\section{g. Hasil Pengujian}

Dapat diambil kesimpulan dari Tabel 1 dan Tabel 2 bahwa prediksi dan hasil perhitungan tersebut hasilnya sesuai dan berbanding lurus dengan rules yang telah ditetapkan.

\section{SIMPULAN}

Kesimpulan yang dapat diambil dari pengolahan data penentuan titik gagalnya sistem transfer cake breaker conveyor dengan memperhatikan kondisi putaran motor cbc dan waktu deteksi dari rotary encoder dapat disimpulkan bahwa :

1. Telah dibuat suatu model yang ditujukan untuk mengimplementasikan logika Fuzzy dengan Inferensi Tsukamoto, dengan memanfaatkan momen inersia sebagai indikator input untuk menentukan titik kegagalan sistem transfer Cake Breaker Conveyor (CBC)

2. Dari hasil pengujian terhadap model prototype bahwa perubahan panjang dan pendeknya As-Screw Conveyor berpengaruh terhadap variabel input variabel output dan hukum kelembaman (momen inersia) yang berlaku pada poros yang berputar

\section{UCAPAN TERIMAKASIH}

Penelitian ini dapat berjalan lancar sesuai dengan rencana berkat dukungan dana dan pegembangan dari berbagai pihak untuk itu penulis ucapkan terima kasih kepada :

1. Direktorat Jendral Penguatan Riset dan Pengembangan Kementrian Riset, Teknologi dan Pendidikan Tinggi Republik Indonesia.

2. Direktur Sistem Riset Dan Pengembangan Kementrian Riset, Teknologi dan Pendidikan Tinggi Republik Indonesia.

3. Ibu Dr.Erlin, M.Kom selaku Ketua dan Bapak Rahmaddeni,M.Kom selaku Kepala LPPM STMIK Amik Riau

4. Rekan rekan dosen dan seluruh civitas akademika STMIK Amik Riau yang telah memberikan dukungan motivasi yang tidak ternilai.

\section{DAFTAR PUSTAKA}

Agus Suandi, Nurul Iman Supardi, A. P.

T. M. U. B. (2016). Analisa

Pengolahan Kelapa Sawit dengan

Kapasitas Olah 30 ton / jam, 2(1), 12-19.

Iswanti, N., Sari, P. R., Si, M., Rusdja, D., Ag, M., \& Padang, K. (2012).

Universitas Andalas Program Studi Agribisnis, (0810222109), 1-12.

Okafor, B. E. (2015). Development of Palm Oil Extraction System.

International Journal of

Engineering and Technology, 5(2), 68-75.

Rahmawati, P., Teknik, J., Alat, M., \& Balikpapan, P. N. (2012). Analisis

Momen Inersia Body Dan

Rotasional Pada Quadcopter, 4(2), 77-83.

Setyopratomo, P. (2012). Produksi

Asam Lemak Dari Minyak Kelapa

Sawit Dengan Proses Hidrolisis, 7(1), 26-31.

Upriyono, S., Zmi, B. A. Y. U. A., Tinggi, S., Nuklir, T., Babarsari, J., \& Pos, K. (2008). Model Simulasi Untuk Optimasi Penentuan Waktu, 25-26. 